\title{
Perspectives
}

Studies in Translatology

\section{Translating onomatopoeia from Chinese into Spanish: a corpus-based analysis}

\section{Helena Casas-Tost}

To cite this article: Helena Casas-Tost (2014) Translating onomatopoeia from Chinese into Spanish: a corpus-based analysis, Perspectives, 22:1, 39-55, DOI: 10.1080/0907676X.2012.712144

To link to this article: http://dx.doi.org/10.1080/0907676X.2012.712144

$$
\text { Published online: } 10 \text { Sep } 2012 .
$$

Submit your article to this journal ¿

Џلll Article views: 514

Q View related articles $\asymp$

View Crossmark data $\nearrow$

4 Citing articles: 1 View citing articles 


\section{Translating onomatopoeia from Chinese into Spanish: a corpus-based analysis}

Helena Casas-Tost*

Departament de Traduccio i Interpretacio, Universitat Autonoma de Barcelona, Bellaterra, Spain

(Received 1 February 2012; final version received 8 July 2012)

This article analyses how Chinese onomatopoeias have been translated into Spanish. It is based on a corpus of seven contemporary Chinese novels and their respective Spanish translations. It begins with a brief overview of the features which distinguish onomatopoeias from other types of words and how the corpus was prepared. This is followed by an analysis of how the translators of the selected novels deal with onomatopoeias seen in the light of Toury's (2004) adequacy-acceptability conceptual framework and the classification of translation techniques proposed by Molina (2006).

This study concludes that, although suppressing onomatopoeias or substituting them for another type of word are common practices, these are not the only possible techniques to transfer these text units. There are other choices that allow for the maintenance of their expressive capacity in the target text (TT), without violating the TT literary system and culture and that depend on the role of the translator in the translation.

Keywords: onomatopoeia; Chinese-Spanish translation; corpus-based translation; acceptability-adequacy.

\section{Introduction}

An onomatopoeia is a type of word with very peculiar characteristics, which often poses a challenge for translators. There are a number of published studies which analyse these text units from a linguistic perspective (Hinton et al., 1994; Voeltz and Kilian-Hatz, 2001; Ibarretxe-Antuñano, 2009) and some from a translation studies approach (Flyxe, 2002; Inose, 2008), focused on languages characterized by lexicons rich in words which come under the heading of ideophones or sound symbolism, ${ }^{1}$ particularly African and Asian languages, Japanese being the prime example. However, there are still few studies which focus on the language combination dealt with in this article: Chinese-Spanish. Although these two languages may not have as many onomatopoeias as other languages, such words are by no means a marginal phenomenon, as advocated by scholars such as Saussure (1954) or more recently Newmeyer (1992), but rather a feature common to all languages, and therefore a phenomenon which has a direct bearing on translation.

As I see it, one of the factors which is an encumbrance to the translator's task is that these text units have been given little importance at a theoretical level and, as a consequence, in practice. This is reflected by the lack of onomatopoeia entries in all

*Email: Helena.Casas@uab.cat 
manner of reference books, including dictionaries, which I believe is one of the reasons why they are rarely used, or even suppressed, in Spanish translations of Chinese works. Omitting source texts (ST) onomatopoeias means that their rich expressive quality is lost, an important consideration for all text types, but perhaps even more so when it comes to literature, since it is not just the content which is important, but also the form. The practice of omitting onomatopoeias is also a common occurrence in other language combinations, such as translating texts in African languages into European ones. Mphande (1992, p. 119) uses the label 'textual genocide' in reference to the attitude of many missionaries and their disciples, whose translations have performed a disappearing act with ideophones, a fundamental component of African languages.

This article attempts to analyse how onomatopoeias have been translated based on a corpus of literary works comprising seven Chinese ST and their corresponding Spanish translations. Although suppressing onomatopoeias or substituting them for another type of word are common practices, it discusses whether these are the best or only possible techniques to transfer these text units as well as the role of the translator in the translation process. It begins with an overview of onomatopoeias from a linguistic point of view and a brief description of how the corpus of this research was put together, followed by an analysis of how the translators from this corpus have handled onomatopoeias based on Toury's (2004) adequacy-acceptability conceptual framework and the translation techniques proposed by Molina (2006).

\section{Onomatopoeias in Chinese and Spanish}

Onomatopoeias fall within the category of words which belong to sound symbolism, however this article is limited to the study of what Hinton et al. (1994) dub 'imitative sound symbolism', that is words that imitate, which I refer to as onomatopoeias.

A distinctive characteristic of onomatopoeias is the peculiar relationship between the signifier and the signified, as they imitate the sound of what they represent. In short, they are words which are phonetically driven, in contrast to Saussure's postulates (1954), noted for defending the view that linguistic signs are assigned arbitrarily. Their peculiar linguistic features distinguish them from the other types of words that make up the lexical stock of all languages and, together with their associated cultural relevance, endow them with an enormous expressive capacity.

At a linguistic level, onomatopoeias are words with uncommon phonological elements and which usually involve vowel alternation and vowel lengthening, or sometimes lengthened consonants, as happens in Spanish. From a morphological perspective, they are characterised by the use of either total or partial reduplication. Although we can find reduplication in other parts of speech, in the case of onomatopoeias this is very frequent and distinctive. Reduplicating onomatopoeias in Chinese is open to a wide range of possibilities compared to other grammar categories, and, furthermore, are the only type of word which Chinese allows to be reduplicated more than once. Syntactically, onomatopoeias operate differently depending on the language. In the language combination studied here, they can perform different roles: in Chinese their adverbial function is a predominant feature, while in Spanish they are often used as nouns or interjections, as corroborated by the data extracted from the study corpus.

As regards semantics, the main characteristic of onomatopoeias is the correlation between the signifier and signified, since the sound they represent in turn constitutes 
what they signify. Allowing for their considerable cultural relevance, what is helpful here is to see whether the semantic fields where they are abundant coincide in Chinese and Spanish, or alternatively, if they tend to polarise towards what Molina (2006) labels 'focos culturales' (cultural focal points), whereby in one language there may be a wide variety of onomatopoeias to refer to a given reality, but few or none in the other language, in which case they are a source of lack of equivalence. Albeit a brief mention here, I believe this to be a crucial consideration for translation studies, however it is not the focus of this article since it requires a more in-depth study, which I will be carrying out later.

Finally, concerning pragmatics, as words which imitate a sound in the real world, onomatopoeias perform a referential function. But, in addition to referring to a sound, onomatopoeias are highly expressive words which also have tremendous allegorical potential, because they can evoke images and arouse feelings in the recipient, thereby performing an expressive function at the same time. Their vivacity, rhythm and musicality means that onomatopoeias also fulfil a stylistic or poetic function, so it comes as no surprise to find them in many and varied contexts, as well as in different text genres, which of course includes literature. This is the case for Chinese, in which they have a considerable bearing in oral language, children's literature and recently in the language used on the internet (Yi 李镜儿, 2005; 2007, pp. 193-200). But they are also a distinctive feature of poetry and novels in Classical and Modern Chinese alike. In Spanish, however, onomatopoeias mainly tend to be relegated to the contexts of oral exchanges, children's literature and the comic genre, particularly when the subject of academic studies, yet we can in fact find them in other contexts, including literature.

Seen from another perspective, scholars such as Childs (2001) relate sociolinguistic factors to the use of onomatopoeias. This is clearly an interesting variable which merits special attention, and is being studied in other languages spoken in Spain such as Basque (Ibarretxe-Antuñano, 2009). However, to date I am not aware of any such studies on the language combination dealt with here.

\section{Translating onomatopoeias: state of the art}

As mentioned earlier, from the perspective of translation, there are very few published studies which look into translating onomatopoeias from Chinese into Spanish at any length. With the exception of the study by Casas-Tost (2009), based on empirical data extracted from a corpus of literary texts, Ramírez (2004) is the only scholar who has raised this issue. In his manual for translating from Chinese to Spanish, he devotes a short section to the translation of Chinese onomatopoeias and expressive words into Spanish. According to Ramírez, expressive words are those which, strictly speaking, do not imitate a sound, but their phonemes do suggest a sound or another sensation, as for example 'murmullo' (murmur) or 'borbotón' (bubbling), and come under the heading of 'conventional sound symbolism' as defined by Hinton et al. (1994).

Ramírez gives great importance to the phonological peculiarities of these words and advocates finding phonological equivalents whenever possible. However, he does allow for the eventuality that this kind of equivalence may not be possible for various reasons: they may not exist in the target language, there may be phonological differences or they could result in cacophony, not forgetting a mismatch in frequency of use. In these cases he opts for not translating onomatopoeias and expressive words 
as such, but rather to find a semantically equivalent or related term. Nevertheless, while he is more inclined to resort to the semantic equivalent in the case of expressive words, he is less so in the case of onomatopoeias, arguing that their sound is the most important component and must be conveyed in the translation. It should be noted that Ramírez's theoretical approach is backed up by ample experience as a translator. As will be seen later, there is a striking difference between his options for translating onomatopoeias and those of other professional translators, who do not appear to have any qualms about suppressing onomatopoeias in their translations from Chinese to Spanish.

With the exception of this author, my research into the state of the art in this matter (Casas-Tost, 2009, pp. 85-104) has not uncovered any other published studies related to the focus of this article. The few that I have found with Spanish as the target language usually work from English and are restricted to the comic genre. One exception is the study by Bueno Pérez (1994), which takes James Joyce's Ulysses as its point of reference and the translation into Spanish by José M. ${ }^{a}$ Valverde. In her analysis she focuses on the degree of lexicalisation in English of the numerous onomatopoeias in the original, concluding that:

Spanish and French tend to lexicalise losing the onomatopoeic value to a greater degree than in English. This leads to the conclusion that this phenomenon thrives more in English, as well as the fact that its writing system has more mechanisms to adapt writing to the original sound. (Bueno Pérez, 1994, p. 25) ${ }^{2}$

In other words, she offers linguistic reasons to explain the lack of onomatopoeias in translations into Spanish when working from languages which have a greater tendency to use them. Although I share the view that the linguistic system in all languages does have a bearing and is a determining factor in translating onomatopoeias, in my view the role of the translator is also a decisive factor. This includes how sensitive the translator is to this phenomenon, as well as the translation norms which govern each translation brief, considerations which will be discussed later in the analysis of my corpus.

\section{Working corpus}

This study is based on the onomatopoeias extracted from a corpus prepared from seven contemporary novels in Chinese that have been translated into Spanish. I chose this genre rather than others more commonly referred to when discussing onomatopoeias, such as comics, as I wish to stress that they are not only limited to registers associated with oral, colloquial or children's language, but also used in high-brow literature and not simply as a superficial embellishment. Another reason for choosing this genre is because onomatopoeias have been marginalised in academic studies, which brings in its wake serious difficulties for translators, due to the lack of available resources.

In addition to period and genre, the third selection criterion was direct translations from Chinese to Spanish, which can prove surprisingly difficult to single out, as revealed by Marín (2008) and Casas-Tost (2009, pp. 116-118). After searching through Spanish translations of contemporary Chinese work, applying these criteria, I chose the following seven works for my working corpus: 
- La blusa roja sin botones (The Red Shirt Without Buttons), by Tie Ning (铁凝) (1984) and translated by T. Fisac (1989);

- La mitad del hombre es la mujer (Half of Man Is Woman), by Zhang Xianliang (张贤亮) (1985) and translated by I. Preciado Idoeta and E. Hu (1986);

- Galera (The Ark), by Zhang Jie (张洁) (1986) and translated by I. Alonso (1995);

- Una caña de pescar para el abuelo (Buying a Fishing Rod for My Grandfather), by Gao Xingjian (高行健) (1989) and translated by L. Ramírez (2003);

- Vivir (To Live), by Yu Hua (余华) (1998) and translated by A. H. Suárez (2010); ${ }^{3}$

- Qingyi. La ópera de la luna (The Moon Opera), by Bi Feiyu (毕飞宇) (2006) and translated by P. Eherenhaus (2007); and

- Mala vida (Vexed Life), by Chi Li (池莉) (2007) and translated by M.C. Espín (2007).

The above account for almost all the works which fulfil these three prerequisites, the one exception being Beipan zhi xia (背叛之夏) by Hong Ying (虹影), translated by Lola Díez in 1998 as El verano de la traición (Summer of Betrayal), which I have not been able to consult in Chinese. Accordingly, I believe that we have here a representative corpus, further validated by the fact that there is no duplication of author, translator or publishing house. This allows for a wide range of onomatopoeia usage in Chinese and samples of how these text units are translated into Spanish, while at the same time minimising possible bias towards individual author or translator idiolects.

\section{Tools used for the analysis and methodology}

Having defined the corpus, the selected texts were then prepared and processed, an entirely manual operation due to the lack of computing tools that allow for working with these two languages. First the onomatopoeias were extracted from the original Chinese works and then collated with their corresponding Spanish translations. The original and translation were then aligned in an Excel spread sheet and both linguistic and translation information obtained for each onomatopoeia, since I consider both aspects to be closely related. In this article, however, I adopt a mainly Translation Studies focused approach.

The analysis was carried out on the basis of both objective and subjective data. The former according to the translation techniques proposed by Molina (2006) and Toury's (2004) adequacy-acceptability conceptual framework, and the latter based on the opinions given in a questionnaire filled out by the translators of my corpus I was able to contact (five out of seven) (Casas-Tost, 2009, pp. 114-115).

I work from the basis of Toury's postulates in his most influential study, Descriptive Translation Studies and Beyond (2004), first published in 1995, where he argues for developing descriptive translation studies as a branch of Translation Studies and proposes a working methodology based on translation norms. The first determines whether the translator is governed by source or target culture text norms, for which we have the associated concepts of adequacy and acceptability, at opposite ends of a continuum. According to Toury, a translation tends towards adequacy if the translator opts for keeping to the norms of the source text culture, while a translation which tends to adapt to the target culture is oriented towards the acceptability pole. 
Regarding Molina's (2006) classification of 18 translation techniques, in this sample I have only been able to identify eight and three cases of paired techniques, below.

- Amplification, which consists of glossing information not formulated in the source text, such as explanatory paraphrasing.

- Discursive creation, that is an ephemeral equivalent, which would not make sense in another context.

- Description, that is replacing a term or expression with a description of its form and/or function.

- Established equivalent, which consists of using recognised terms or expressions (reflected in dictionaries or usage) as a target language equivalent.

- Generalisation, which is the use of a more general or neutral term.

- Borrowing, that is incorporating a word or expression as it is from the source language.

- Reduction, which consists of suppressing information conveyed by the ST in the TT, either partially or completely.

- Finally, substitution, which I have redefined with respect to Molina because it was originally understood as substituting linguistic elements for paralinguistic elements, or vice versa, and did not correspond to the data obtained from this corpus. Here, substitution is taken as translating an onomatopoeia according to its meaning but dispensing with its onomatopoeic form, as illustrated by the following example.

Example 1

(a) 我脑袋嗡的一下。(YH, p. 26) ${ }^{4}$

(b) Wo naodai weng de yixia.

(c) My head weng part. a little.

(d) Me zumbó la cabeza. (AHS, p. 37) [My head was buzzing.]

In addition, the three following paired techniques were recorded: substitution + amplification, substitution + particularisation and generalisation + reduction.

\section{Results and analysis}

From a total of 490 onomatopoeias extracted from the corpus of Chinese texts, only $82(16.7 \%)$ were translated into Spanish with the same type of word. From a broad view, three main tendencies were identified when translating Chinese onomatopoeias into Spanish, which are as follows in order of frequency:

- substitution of the original onomatopoeias for another type of word other than an onomatopoeia (50.6\%);

- omission of source text onomatopoeias in the target text $(32.6 \%)$; and

- translation of source text onomatopoeia using a target language onomatopoeia $(16.7 \%)$.

These three tendencies depend on various factors: on the one hand, the type of onomatopoeia, availability and frequency of use in the target language, and on the other hand, the method and approach adopted by the translators. In other words, 
both linguistic issues as well as the personal choices by each translator are key factors when translating onomatopoeias and all of these are embodied in the translation techniques chosen in each case.

If we take into account the techniques used, summarised in Figure 1 in round numbers, we can see that those which entail using onomatopoeias in the translation (such as an established equivalent, borrowing or discursive creation) rank very low, while in contrast, those which suppress or modify them in one way or another rank very high. So, priority is given to content over form.

\section{Translation Techniques}

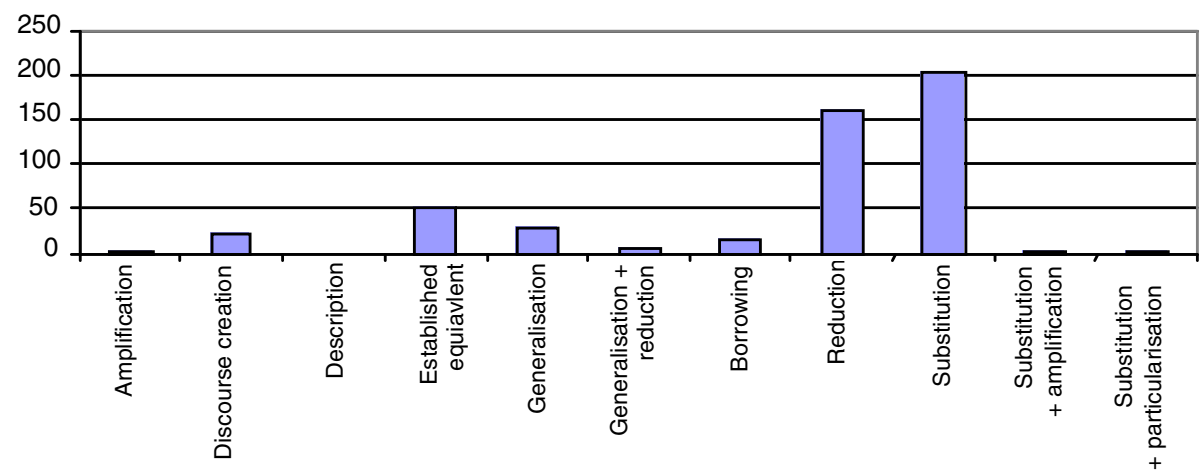

Figure 1. Translation techniques used to translate onomatopoeias from Chinese into Spanish.

\section{Translating onomatopoeias: main tendencies}

Substituting onomatopoeias for another type of word

We have already seen that in half of the cases where there is an onomatopoeia in Chinese, the translators opted for conveying it by means of another type of word, with the ensuing loss of the phonetic intention in the source text. However, in $50 \%$ of these cases, another type of ideophone was used which, while not being imitative, does have a distinctive expressive and phonological relevance. This may well reflect that the translators are aware of the peculiar qualities of these type of words or could also be due to the fact that in bilingual dictionaries many Chinese onomatopoeias are generally not translated for onomatopoeias, but rather by other types of words, in many cases expressive words, according to Ramírez's understanding of the term explained earlier, as in the following example.

Example 2

(a) 听得见的只是头顶上树叶子在微风中飒飒声响 [...]. (GXJ p. 221)

(b) Tingdejian de zhi shi touding shang shuyezi zai weifeng zhong sasa shengxiang [...].

(c) Listen-part.-see part. only is top-loc. tree leaf in gentle breeze-loc sasa-sound. 
(d) El único sonido es el murmullo de la brisa entre las hojas de los árboles [...]. (LR, p. 54) [The only sound that could be heard was the murmur of the breeze through the leaves of the trees].

Apart from substitution, the main technique used to translate an onomatopoeia for another type of word ( $41 \%$ of the cases), the other techniques I associate with this tendency are generalisation $(5.9 \%)$, discursive creation $(1.2 \%)$, description (only one case, that is $0.1 \%$ ) and the three paired techniques mentioned earlier $(1.8 \%)$.

In addition to the translation techniques used, I also believe that it is expedient to look at the semantic fields these words belong to. According to this corpus, substitution is the most commonly employed technique to translate all types of onomatopoeias, with the exception of those which refer to actions for which Spanish has many, as the next example shows.

Example 3

(a) “味嚓嚓”地一声巨响, 一棵大树被刮倒了[...]. (ZJ p. 95)

(b) "Kachacha" de yi sheng juxiang, yi ke da shu bei guadao le [...].

(c) onomatopoeia of noise of breaking-part. one sound loud sound, one class. big tree-passive part. blow down-part.

(d) ¡Crac! Acaban de oír un ruido, el de la caída del un árbol [...]. (IA, p. 125) [Crack! They just heard a sound, that of a tree falling down].

However, substitution is a particularly conspicuous technique in the case of onomatopoeias referring to animals and natural phenomena, which in this corpus are almost invariably translated with expressive words. While those related to animals are perhaps the first which come to mind when we talk about onomatopoeias, my corpus illustrates that Spanish has mechanisms to express these types of sounds, which do not always entail using onomatopoeias. In other words, the semantic class of onomatopoeias is a determining factor when it comes to translating them and whether to use the same type of word or not.

\section{Omitting onomatopoeias in the target text translation}

Reduction is the technique which ranks second, accounting for almost one third of the cases. This technique implies the complete loss of the phonetic intention in the source text, as shown in the following example.

\section{Example 4}

(a) 他“嚓”地又点了一支烟 [...]. (CL, p. 42)

(b) Ta "cha" de you dianle yi zhi yan [...].

(c) He cha-part. again lit up-part. one clas. cigarette.

(d) Volvió a encender un cigarrillo [...]. (MCE, p. 53) [He lit up another cigarette].

This loss, however, is not due to the lack of equivalents in Spanish, since I was able to confirm that, for instance, two bilingual dictionaries list $75 \%$ of the onomatopoeias that appear in Chinese. The translator's choice to suppress them is governed by the 
translation method s/he has chosen and possibly by factors related to how frequently they are used and the available repertoire of onomatopoeias in each language.

By way of example, 15 different variants were recorded from over 100 occurrences of onomatopoeias which imitate laughter in Chinese, of which 60 were entirely suppressed in the Spanish translations (Example 5). Those that were translated as onomatopoeias were translated in six different ways, two of these being Chinese loan words. Moreover, in the Spanish translations all the laughter onomatopoeias appear in dialogues, while in Chinese the majority are expressed by the narrator's voice (Example 6).

\section{Example 5}

(a) “我怎么不知道?” 她扑哧一笑。(ZXL, p. 120)

(b) “Wo zenme bu zhidao?” Ta puchi yi xiao.

(c) I how not know? She puchi (onomatopoeia of chuckling) one laugh.

(d) ¿Cómo no voy a saberlo? -soltó la risa. (IP \& EH, p. 301) [How could I not know it? -She laughed].

Example 6

(a) “嘿嘿! 我也运气。”(ZXL, p. 10)

(b) "Hei hei! Wo ye yunqi.

(c) Hei hei (onomatopoeia of laughter) I also luck.

(d) ¡Je, je! También yo he tenido suerte. (IP \& EH, p. 44) [He he! I've also been lucky].

From this, one can draw two conclusions: Spanish has a less varied repertoire of laughter onomatopoeias, and it tends to use onomatopoeias more in direct speech. So, it is hardly surprising that fewer onomatopoeias have been used in the target text than in the original Chinese, or that translators have opted for techniques which involve suppressing them either partially or completely.

However, onomatopoeias are not eliminated to the same degree across different semantic fields, as is the case with onomatopoeias related to actions such as a fall, where we can find a rich repertoire of onomatopoeias in Spanish. Consequently, as in the case of substituting, I consider the semantic field to be a key parameter when it comes to choosing a translation technique that either uses, transforms or omits ST onomatopoeias in the translation.

\section{Translating onomatopoeias using onomatopoeias}

Translating an onomatopoeia in Chinese for a formal equivalent in Spanish ranks lowest and is the least statistically significant of the three main translation tendencies observed in this corpus. Although it accounts for $16.7 \%$ of the cases, it is the only one which maintains the phonetic intention of the original, including resorting to a direct Chinese loan word. The four translation techniques used in this modality are: established equivalent (57\%), discursive creation (24\%), borrowing (17\%) and amplification $(2 \%)$.

If we analyse the cases where Chinese onomatopoeias have been translated to Spanish onomatopoeias, two features stand out. First, from a linguistic point of view, 
we are more likely to find formal equivalents for onomatopoeias which imitate sounds related to actions, and furthermore, mainly as interjections, as in Example 3. Second, from a Translation Studies perspective, we can see that the translator plays a decisive role, since only some of the translators have used techniques that involve maintaining the onomatopoeias in the target text, and their respective approaches are completely different. Accordingly, while the only two cases of amplification and the majority of cases involving discursive creation are attributable to the translator of the work by Yu Hua (余华), the majority of cases when loan words have been used is in the translation by Preciado and $\mathrm{Hu}$. All of this reflects the different translation methods used by the translators and where they can be situated along Toury's adequacy-acceptability continuum, an aspect which I shall develop further in the next section.

\section{The role of the translators}

In addition to linguistic factors, among which I believe the semantic factors to be a prominent feature, translators also play a decisive role in how onomatopoeias are translated. If we compare the number of onomatopoeias in the source texts with those in the target text translations, we can appreciate that the proportion of onomatopoeias translated by the same type of word is really quite low, as shown in Figure 2 (round figures (first two columns) and percentages (third column)). Although there is a significant drop in the number of onomatopoeias when we move from the Chinese ST to the Spanish TT in these seven works, one can appreciate that how they are handled varies depending on the translator. Accordingly, there are those, such as Eherenhaus and Espín, who rarely use onomatopoeias in their translations; others, such as Fisac, who use them a great deal; and the rest, who use them more or less to the same degree, around $20 \%$ of those in the original texts.

Comparison of onomatopoeias used ST - TT

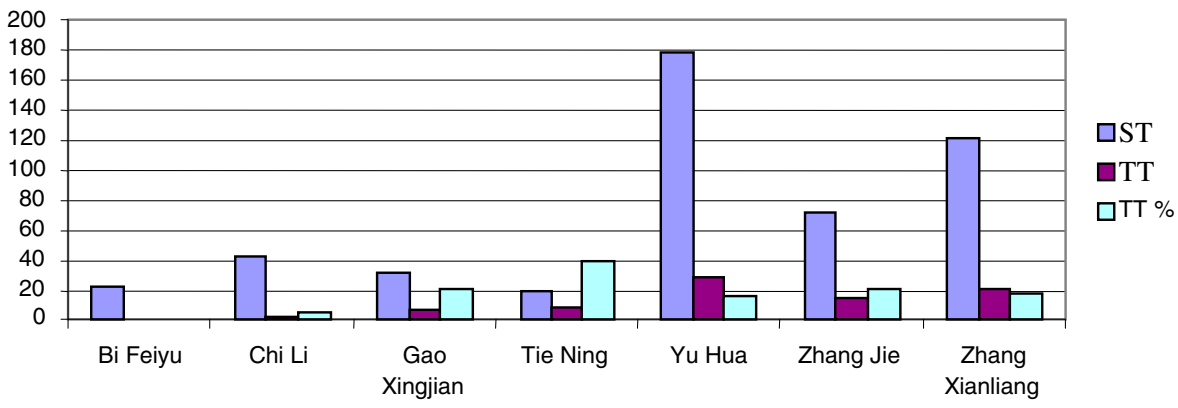

Figure 2. Comparison of onomatopoeias between the ST and TT.

However, while there are far fewer onomatopoeias used in the Spanish translations, a common practice is to replace them with what Ramírez refers to as 'expressive words', thus minimising the loss of their highly distinctive phonological component, as in Example 2. Figure 3 illustrates how half of the translators compensate for the absence of onomatopoeias in their translations by using 
Distribution of onomatopoeias and expressive words in TT

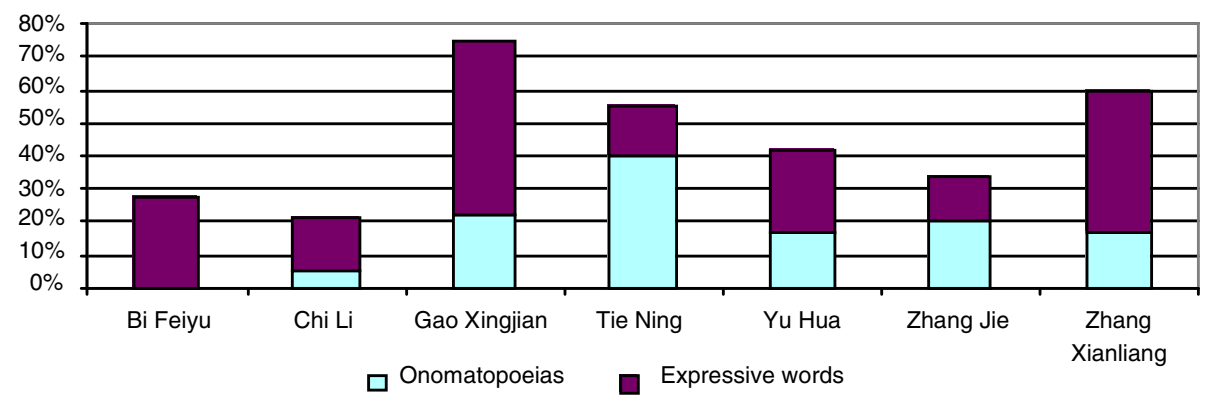

Figure 3. Distribution of onomatopoeias and expressive words in each translation.

expressive words, a strategy adopted in more than $50 \%$ of the cases where there is an onomatopoeia in the Chinese text. The clearest example of this strategy is the translator of the work by Gao Xingjian (高行健), who transforms $75 \%$ of the Chinese onomatopoeias into either expressive words or onomatopoeias. Only two of the translators - the novels by Tie Ning (铁凝) and Zhang Jie (张洁) - show a clear preference for onomatopoeias in their Spanish translation, while the rest make greater use of expressive words than onomatopoeias. At the other extreme, we find Eherenhaus and Espín, the translators of the works by Bi Feiyu (毕飞宇) and Chi Li (池莉), respectively, who almost invariably use expressive words only.

Taking the analysis a step further, if we look at the techniques used in the seven translations we can see noteworthy differences which reveal an attitude and positioning towards translating this type of word, which in turn reflect the translation method behind each translation brief.

Both Eherenhaus' and Espín's translations are conspicuous for their absence of onomatopoeias (none and two, respectively) and for the fact that they do not compensate for this reduction with other words which would maintain the phonetic intention in the Chinese ST. The predominant techniques used in both translations are reduction and substitution, even in cases of words from semantic fields where there is a wealth of onomatopoeias in Spanish. In fact, Espín does not consider whether onomatopoeias are used differently in Chinese and Spanish, and consequently does not afford them any specific treatment in her translation. Both translators favour the semantic content of the onomatopoeias over their phonological characteristics in their Spanish translations and are inclined to paraphrase them when they cannot find a formal equivalent.

In contrast, Fisac, who translated Tie Ning (铁凝), has translated the highest proportion of onomatopoeias for onomatopoeias, and who has resorted least to expressive words to replace them. We can see a clear attempt to maintain the onomatopoeias in the target text translation, even in cases where they are not listed in reference works such as dictionaries, resorting to a loan word in one case. In Fisac's opinion, as stated in the questionnaire she filled in, onomatopoeias are a type of word which pose a particular problem, as they are text units that do not have equivalents in both languages. Her standpoint is 'first and foremost to give priority to literalness' ('primar ante todo la literalidad') when translating from Chinese to Spanish, which entails not only maintaining the semantic content of the original, but 
also its formal attributes. So, it is hardly surprising that this is the translation with the highest number of onomatopoeias translated into Spanish by the same lexical unit.

Alonso, who translated the work by Zhang Jie (张洁), also translated many of the onomatopoeias in the original Chinese work for onomatopoeias, using techniques involving established equivalents and borrowing. However, on many occasions she also opts for reduction, which suggests a somewhat ambiguous stance regarding negotiating these text units; a matter I have been unable to clarify as I could not contact her.

In the translation of Zhang Xianliang (张贤亮) by the Preciado and $\mathrm{Hu}$ tandem, the conspicuously high number of ideophones used to translate Chinese onomatopoeias (almost 60\%) suggests that they are apparently aware of the sound characteristics of these words, which figure in significant numbers in the original. They have only translated $17 \%$ of the Chinese onomatopoeias for the same type of word, and substitution, reduction and generalisation rank highly among their repertoire of translation techniques. However, an illustrative feature is that this translation makes the most use of loan words, even for onomatopoeias relating to human beings, which is the class of onomatopoeia where they are most abundant in Spanish in this corpus.

In the translation of the work by Gao Xingjian (高行健) by Ramírez, one can see a certain balance between techniques which involve suppressing the onomatopoeias in Chinese and those which favour using them in the Spanish translation, particularly the use of loan words. Ramírez maintains the form as much as possible in his translation and when he is unable to find a suitable onomatopoeia he tries to find another type of ideophone. Bearing this in mind, he is the translator who has most successfully maintained the expressiveness of the ST, as shown in Figure 2. Similarly, he is of the opinion that each case must be studied individually according to the context, always trying to maintain the style and idiomatic nature of the ST, which can be reflected by using this type of word.

Finally, the translation of the work by Yu Hua (余华) also maintains a certain balance between techniques which favour preserving the onomatopoeias and those which tend to erase them from the translation. While it shares features in common with the rest of the translations in this corpus - extensive use of substitution and reduction - at the same time it reveals certain peculiar features which require further comment.

On the one hand, along with the two predominant techniques, Suárez makes abundant use of established equivalent and discursive creation when translating onomatopoeias, but, in contrast, at no moment resorts to loan words. In fact, she is the most prodigious at creating onomatopoeias in Spanish; when she cannot find a suitable onomatopoeia in Spanish, she prefers to create her own rather than a Chinese loan word. Although she is not the only translator to do so, her discursive creations account for half of those in this corpus, and this creativity goes as far as being responsible for all the proto-lexical items recorded, ${ }^{5}$ two of which are given in the following examples.

\section{Example 7}

(a) [...] 羊沙沙地吃着草 $[\ldots]_{\mathrm{o}}(\mathrm{YH}, \mathrm{p} .83)$

(b) [...] yang shasha de chizhe cao [...]. 
(c) [...] sheep shasha-part. eat-part. grass [...].

(d) [...] el ruido que hacía al masticar - shh, shh- parecía de lluvia. (AHS, p. 120) [the sound it made when chewing - shh, shh- seemed like rain].

Example 8

(a) 有一阵子下起了雪珠子, 打在门窗上沙沙乱响 (YH, p.133)

(b) You yizhenzi xiaqile xue zhuzi, dazai menchuanshang shasha luan xiang.

(c) There is a while fall begin-part. snow pearls, hit on door window-loc. shasha disorderly sound.

(d) Durante un rato estuvo cayendo granizo menudo, que iba dando en las ventanas, ¡cshh! ¡cshhh! (AHS, p. 185) [For a time a light hail was falling that dashed against the windows, cshh!, cshh!].

Firstly, as opposed to the rest of the translators, whose discursive creations are restricted to onomatopoeias for actions or objects, Suárez's creations are spread across four of the five semantic categories in which I classified the ST onomatopoeias (Casas-Tost, 2009, pp. 168-199). Consequently, this needs to be understood as a distinctive feature of this translator's style, which reflects an individual and specific translation method and a personal sensitivity towards translating words with a significant phonological force.

Secondly, she uses a more diverse range of onomatopoeias in Spanish, to the degree of giving three different translation options for the same onomatopoeia, or two different ones as in Examples 7 and 8. This diversification is as much the case when employing onomatopoeias as when she substitutes them for another type of word or paraphrases, all of which imbue the translation with great wealth in keeping with the original text.

In contrast, she is the only translator who uses amplification and among the few who combined this with substitution or glossing. When employing this technique to translate onomatopoeias, she often resorts to apposition combined with an explanation of the sound, as can be seen in Example 9.

Example 9

(a) 我的拖鞋吧哒吧哒, 把那些小道弄得尘土飞扬, 仿佛是车轮滚滚而过时的情景。(YH, p. 3)

(b) Wo de tuoxie badabada, ba na xie xiaodao nong de chentu feiyang, fangfu shi chelun gungun er guoshi de qingjing.

(c) My-part. flip flops badabada, prep. those trails to do-part. dust stir up, seem to be cart wheels roll and pass-part. scene.

(d) [...] con las chanclas chasqueando -tris tras, tris tras-y levantando nubes de polvo como si fueran estrepitosas ruedas de carro. (AHS, p. 5) [with his flip flops clacking - clack, clack, clack, clack - and stirring up clouds of dust as if they were rackety cart wheels].

Suárez states that she does not adopt a specific approach when translating Chinese onomatopoeias into Spanish, arguing that each case has to be dealt with individually. However, she maintains that for this language combination they pose a particular problem for the translator, due to differences in frequency of use and register in each language and that there is no reason why the sounds or the feelings they evoke should coincide in both cultures. Although she acknowledges having suppressed 
onomatopoeias from the many in the Chinese ST, she is of the opinion that they must be preserved as much as possible in the translation, particularly because of their phonological value (either adapting them to Spanish or creating them). Otherwise, she believes they should either be substituted where possible for another word of onomatopoeic origin or that they should comprise expressive sounds, always depending on their importance in the text and the context where they occur. In other words, this translator is clearly aware of the role these onomatopoeias occupy in the Chinese ST and attempts to maintain them in the TT translation.

Having given this brief analysis of the seven translations that make up this corpus, and turning once again to Toury's terminology (2004), we can place them along the adequacy-acceptability continuum, as illustrated in Figure 4.

\begin{tabular}{|c|c|c|}
\hline Adequacy & & Acceptability \\
\hline $\begin{array}{ll}\text { Fisac } & \\
& \text { Alonso } \\
& \text { Preciado y Hu }\end{array}$ & $\begin{array}{l}\text { Ramírez } \\
\text { Suárez }\end{array}$ & $\begin{array}{c}\text { Espín } \\
\text { Eherenhaus }\end{array}$ \\
\hline
\end{tabular}

Figure 4. Adequacy-Acceptability continuum.

At the acceptability end of the continuum we find the translations by Eherenhaus and Espín, since they stress the target text culture linguistic and literary conventions and appear to give little importance to these text units. Instead, they opt for diluting onomatopoeias in the target text, arguing that their semantic value is more important than their phonological value and that they are not used to the same degree nor with the same frequency in Spanish as in Chinese. At the adequacy pole we can place Fisac, and to a certain degree Alonso and the Preciado-Hu team, because of their tendency to adopt loan words and to preserve the onomatopoeias in their respective translations. Midway between the two extremes we have Ramírez and Suárez, who not only give importance to onomatopoeias and their expressive value in Chinese, but in addition achieve a natural and fluent transfer into Spanish. This can run from creating their own onomatopoeias, using Chinese loan words, substituting them for another type of word to reformulating, which preserve the expressiveness of the original as much as possible.

\section{Conclusions}

In this article I have broached the question of how onomatopoeias have been translated from Chinese into Spanish based on a representative corpus of contemporary Chinese novels. I have preferred to approach this more from a Translation Studies perspective rather than linguistic, based on Toury's (2004) postulates and using Molina's (2006) proposed list of translation techniques as a tool, but without overlooking linguistic considerations, which are also important when translating onomatopoeias.

From a broad perspective, three main tendencies emerge when translating onomatopoeias, namely, in order of frequency, substituting with a non-onomatopoeic word and suppressing and using onomatopoeias in the target text. Although 
this ranking is clearly reflected in the seven works studied, what distinguishes them is when onomatopoeias are transferred to Spanish using techniques such as an established equivalent, borrowing, discursive creation and amplification or compensating for the lack of TT onomatopoeias with another type of ideophone.

Accordingly, and based on the principles posited by Toury, I have observed tendencies and attitudes by the translators in this corpus that situate them at different points along the adequacy-acceptability continuum. On the one hand, we have a new generation of translators, comprising Eherenhaus and Espín, who do not appear to give much importance to the phonological and expressive value of onomatopoeias and give priority to producing a natural-sounding TT, a language in which onomatopoeias are comparatively less frequent than in Chinese, although far from non-existent. In short, they give priority to acceptability over adequacy. At the other extreme of the continuum, we have translators who adopt techniques which reflect a stronger tendency to maintain the Chinese onomatopoeic features, at times bordering on a literal translation, as stated by one of the translators, but who are not governed solely by adequacy. Between the two extremes we find experienced translators who also make attempts to keep the expressive value of the onomatopoeias in their translations, although also keeping well in mind the principle of acceptability.

In short, there is no unanimous agreement over how to negotiate onomatopoeias, since this is determined by the method adopted by the translator, the guidelines which govern each of the translations and the individual style of each translator, which also includes varying degrees of awareness about where they stand theoretically when it comes to translating onomatopoeias, according to those I have been able to consult. However, although there is no single correct or incorrect criterion, I have been able to clearly demonstrate that the hackneyed techniques of reduction and substitution are not the only ones which translators use, but rather there are others which allow for using onomatopoeias, whether these are typical and commonly used in Spanish, Chinese loan words or original discursive creations. Even more important is the fact that using these techniques does not necessarily mean a text that does not flow well, sounds vulgar or infantile, but rather that there are translators such as Suárez or Ramírez who have shown that it is possible to create a text which can conserve both the semantic and expressive content of onomatopoeias, which Diffloth had identified as far back as 1972 as most difficult when it comes to translating ideophones, including onomatopoeias.

\section{Acknowledgements}

This article has received the support of TXICC (Chinese-Spanish/Catalan Translation Research Group), of the Department of Translation and Interpreting (UAB) and InterAsia Research Group, recognised and funded by the Generalitat de Catalunya (2009 SGR-GRC 1103). I am grateful to Sara Rovira-Esteva for her helpful comments on an earlier version of this paper.

\section{Notes}

1. See Hinton, Nichols and Ohala (1994) for a detailed study on this topic, and IbarretxeAntuñano (2009) for an in-depth review of this term and the different terms related to this linguistic feature. 
2. The original text reads as: 'El español y el francés tienden a lexicalizar perdiendo el valor onomatopéyico en mayor proporción que el inglés. Esto trae como resultado que el fenómeno sea más fecundo en la lengua inglesa, así como que este sistema tiene más mecanismos para adecuar la grafía al sonido originario'.

3. I would like to thank A.H. Suárez for entrusting me with the manuscript of her translation prior to its publication.

4. The information given in brackets refers to the authors and translators of the works and corresponding page number where they appear. For each occurrence I give: the original Chinese, a pinyin transcription, a literal translation in English and the published Spanish translation and a translation into English in brackets. In addition, the onomatopoeias are underlined in all languages to see them easily.

5. Proto-lexical items are written representations of sounds which violate the structure of the language, often made up of lengthened consonants without vowels, for example 'brrrr' or 'zzzzzzz'.

\section{Notes on contributors}

Helena Casas-Tost, B.A. in Translation and Interpreting, Ph.D. in Translation and Intercultural Studies from the Universitat Autònoma de Barcelona. She lectures on Mandarin Chinese and Translation from Chinese into Spanish at the Faculty of Translation and Interpreting (Universitat Autònoma de Barcelona) and also works as a professional translator. Her research interests include Translation Studies, Teaching Chinese as a Foreign Language and Contrastive Linguistics. She has published a number of articles on Chinese-Spanish translation, Chinese linguistics and teaching Chinese as a foreign language.

\section{References}

Bueno Pérez, M.L. (1994). La onomatopeya y su proceso de lexicalización: notas para un estudio. Anuario de estudios filológicos, 17, 15-26.

Casas-Tost, H. (2009). Análisis descriptivo de la traducción de las onomatopeyas del chino al español (Unpublished doctoral dissertation). Universitat Autònoma de Barcelona, Spain.

Childs, G.T. (2001). Research on ideophones, wither hence? The need for a social theory of ideophones. In L. Voeltz \& C. Kilian-Hatz (Eds.), Ideophones (pp. 63-73). Amterdam and Philadelphia, PA: John Benjamins.

Diffloth, G. (1972). Notes on expressive meaning. Papers from the Regional Meeting of the Chicago Linguistics Society, 8, 440-447.

Flyxe, M. (2002). Translation of Japanese onomatopoeia into Swedish (with focus on lexicalisation). Africa \& Asia, 2, 54-73.

Hinton, L. et al. (Eds.) (1994). Sound symbolism. Cambridge: Cambridge University Press.

Ibarretxe-Antuñano, I. (2009). Onomatopeyas del euskara: análisis y ejemplos Retrieved from http://www.unizar.es/linguisticageneral/articulos/Ibarretxe-Basque-onomatopoeia-09.pdf

Inose, H. (2008). Translating Japanese onomatopoeia and mimetic words. In A. Pym \& A. Perekrestenko (Eds.), Translation research projects 1 (pp. 97-116). Tarragona: Intercultural Studies Group.

Marín, M. (2008). La traducción indirecta de la narrativa china contemporánea al castellano: ¿síndrome o enfermedad? Revista de historia de la traducción, 2, 2. Retrieved from http:// www.traduccionliteraria.org/1611/art/marin.htm

Molina, L. (2006). El otoño del pingüino. Análisis descriptivo de la traducción de los culturemas. Castelló de la Plana: Publicacions de la Universitat Jaume I.

Mphande, L. (1992). Ideophones and African verse. Research in African Literatures, 23, $117-$ 129.

Newmeyer, F. (1992). Iconicity and generative grammar. Language, 68, 423-430.

Ramírez, L. (2004). Manual de traducción chino/castellano. Barcelona: Gedisa.

Saussure, F. (1954). Curso de lingüística general. Buenos Aires: Editorial Losada.

Toury, G. (2004). Los estudios descriptivos de traducción y más allá. Metodología en estudios de traducción. Madrid: Cátedra. 
Voeltz, F.K.E., Kilian-Hatz, C. (Eds.) (2001). Ideophones. Amsterdam/Philadelphia: John Benjamins.

Yi， K. 李镜儿 (2005). Xiandai Hanyu huanjing zhong de nishengci yingyong 现代汉语环境中的拟声词应用 [Use of onomatopoeia in modern Chinese]. In Wu Zhaolu 吴兆路, Kai Sooji 甲斐胜二, \& Lin Junxiang 林俊相 (Eds.), Zhongguoxue yanjiu (Vol. 8) (pp. 355-359). Jinan: Jinan chubanshe.

Yi, K. 李镜儿 (2007). Xiandai Hanyu nishengci yanjiu 现代汉语拟声词研究 [Onomatopoeias in Modern Chinese]. Shanghai: Xuelin chubanshe.

\section{References for the corpus}

Bi, F. 毕飞宇 (2006). Qingyi 青衣 [The Moon Opera]. Retrieved from http://www.my285.com/ ddwx/qingyi/index.htm

Bi, F. 毕飞宇 (2007). Qingyi. Ópera de la luna. (P. Eherenhaus, Trans.). Barcelona: Verdecielo.

Chi, L. 池莉 (2007). Fannao rensheng 烦恼人生 [Vexed Life]. Retrieved from http://wylib. jiangmen.gd.cn/book2/dbook2/T0114/0141.pdf

Chi, L. 池莉 (2007). Triste vida. (M.C. Espín Trans.). Barcelona: Belacqva.

Gao, X. 高行健 (1989). Gei wo laoye mai yugan 给我老爷买鱼笔 [Buying a Fishing Rod for My Grandfather]. Taipei: Lianhe wenxue.

Gao, X. 高行健 (2003). Una caña de pescar para el abuelo. (L. Ramírez, Trans.). Barcelona: Ediciones del Bronce.

Tie, N. 铁凝 (1984). Meiyou niukou de hong chenshan 没有钮扣的红祄衫. Beijing: Zhongguo qingnian chubanshe.

Tie, N. 铁凝 (1989). La blusa roja sin botones. (T. Fisac, Trans.). Madrid: Ediciones SM.

Yu, H. 余华 (1998). Huozhe 活着 [To live]. Haikou: Nanhai chubanshe.

Yu, H. 余华 (2010). Vivir. (A.-H. Suárez, Trans.). Barcelona: Seix Barral.

Zhang, J. 张洁 (1986). Fangzhou 方舟 [The Ark]. In Zhang Jie ji [Zhang Jie's Anthology]. Fuzhou: Haixia wenyi chubanshe. pp. 1-110.

Zhang, J. 张洁 (1995). Galera. (I. Alonso, Trans.). Tafalla: Editorial Txalaparta.

Zhang, X. 张贤亮 (1985). Nanren de yiban shi nüren 男人的一半是女人 [Half of man is Woman]. Retrieved from http://book.kanunu.cn/html/2005/0731/656.html

Zhang, X. 张贤亮 (1986). La mitad del hombre es la mujer. (I.P. Idoeta \& E. Hu, Trans.). Madrid: Ediciones Siruela. 